\title{
Symposium: Does Cross-Cultural Philosophy Stand in Need of a Hermeneutic Expansion?
}

\begin{abstract}
Does cross-cultural philosophy stand in need of a bermeneutical expansion? In engaging with this question, the symposium focuses upon methodological issues salient to cross-cultural inquiry. Douglas L. Berger lays out the ground for the debate by arguing for a methodological approach, which is able to rectify the discipline's colonial legacies and bridge the hermeneutical distance with its objects of study. From their own perspectives, Hans-Georg Moeller, Paul Roth and A. Ragburamaraju analyze whether such a processual and hermeneutically-sensitive approach can indeed open up new hermeneutic horizons. Their responses shed light upon cross-cultural philosophy's continued embedment in Euroamerican professional philosophy and how the locality of its knowledge-seeking endeavors may indeed have repercussions on attempts to bridge temporal and spatial distances.
\end{abstract}

Keywords: colonialist expansion; cross-cultural philosophy; comparative philosophy; intellectual hegemony; understanding; translation

\section{Cross-Cultural Philosophy and Hermeneutic Expansion}

\section{DOUglas L. Berger}

Southern Illinois University, Carbondale, USA (dberger@siu.edu)

This short essay arises out of my career so far in cross-cultural philosophy. Cross-cultural philosophy is certainly not a discipline governed by a priori principles. We cannot know in advance, that is, what sorts of resonances, differences, conversations, incommensurable features and so on will emerge from bringing a thinker or idea from one tradition into engagement with another. Neither can we know, beforehand, what sorts of methodological approaches will be appropriate to conducting cross-cultural conversation; the best approaches emerge from the process and the experiences drawn from it. It is, both for individual researchers and cultures, an activity in which certain lessons may be learned through the course of time; the process is what provokes our learning. Where do we stand after recent centuries of cross-cultural philosophical engagements between various Western and Asian traditions, and should such a stock-taking provoke us to alter approaches that have been employed so far? The examples I will employ in what follows are drawn from the areas in which I have worked, namely the Indian, Chinese and Continental European traditions, but hopefully the ideas I will discuss here will be relevant to other spheres of thought in these spheres of dialogue.

There are, in my view, two fundamental difficulties with what has passed for "comparative philosophy" as it has been largely practiced in the past five hundred years. The first of these difficulties is that it has grown out of colonial contexts, in which European and American military and economic power has led to conquest, domination and homogenization of other cultural traditions across the globe. In these admittedly complex contexts, Western philosophies, despite their historically provincial frameworks and categories, were erected as 
the standards for universal thought and truth, while the philosophical traditions they confronted were often either measured against Western standards or dismissed as "unphilosophical." Even when native cultures responded to such Western representations and vilifications of their heritages of thought in these centuries, they often did so by attempting to demonstrate that the West's very ideals of universality and truth were better fulfilled by those heritages than by the systems of the West. ${ }^{1}$ The second fundamental problem of modern "comparative philosophy" is what has come to be called the problem of "prejudice" as it is connected to the "hermeneutic circle" (Gadamer 1994). In short, if we are bound, as the historical beings we are, to encounter other traditions at first through our own tradition's language, conceptual framework and civilizational prejudices, then the likelihood of completely abandoning these in the attempt to "understand" another cultural tradition has but dim prospects. While Gadamer, who formulated this version of the problem, took a positive tack in seeing our prejudices as inescapable conditions of initiating a kind of dialectic interchange between reader and text, and Ricoeur thought readers in these circumstances could attain expanded capacities for "projecting themselves" into a text and another "lifeworld," the dangers implicit in such prejudices are still obvious (Ricoeur 1981: 192). When we look at other traditions, we not only look as ourselves, but often for ourselves in them. Resisting these legacies of recent "comparative philosophy" is indeed no easy matter. But perhaps we entertain impossible expectations of ourselves to begin with when we strive for a transcending, an escape, from our historical and hermeneutic situatedness in an attempt to arrive at some abstracted "neutral" stance in comparative studies. Are there ways we may be able to, not so much break out of the "hermeneutic circle" or pretend that we are not heavily influenced by the legacies of colonialism, but perhaps expand our hermeneutic boundaries instead, and forge overlappings with other "circles" of thought, creating new relationships between cultures?

Of course, growing up in any modernized cultural tradition and being trained from within a westernized academic system hardly makes anyone, practically anywhere, immune from either the legacies of colonialism or hermeneutic distance. The challenges of engaging with ancient facets of a cultural tradition may be different for those who do so from within the inherited and internally developed interpretive frameworks of that tradition, but for those who have been trained or influenced by western academic and civilizational mores, the effects of modernization and hermeneutic distance will be felt by the Indian or Chinese researcher with regard to their own culture's past. The prevailing ideals of contemporary life, which have been thoroughly transformed by the market forces of a globalizing economy, and the variously inflected secular trends of professionalized academic research, themselves results of westernization, facilitate much of what we take to be philosophical writing, teaching and interchange today. Furthermore, it is not as if any of us has a crystal ball that would enable us to peer into the ancient "lifeworlds" of philosophers even in one's own traditions to divine what they were thinking or what the exact meanings and intentions of their ideas and texts were. So, historical distance itself is a potential barrier for the scholar, whether they are doing cross-cultural thought or investigating the ancient texts of a tradition that is supposedly their "own." And this historical distance constitutes a good portion of the problem of the hermeneutic circle. ${ }^{2}$ Is it a barrier that we cannot hope to traverse at all, or are there degrees to which we can venture out beyond our own boundaries?

There are various strategies for "coping," as it were, with the hermeneutic problem of "distanciation." One of the more widespread strategies as of late is the invocation, valid as far as it goes, of ever-present and ever-transforming cultural "hybridity." Cultural and intellectual traditions were, at the time of the composition of classical texts of any period, in various phases of hybrid influences and forms, and this can certainly also be said of our contemporary circumstances. ${ }^{3}$ This condition of dynamic hybridity would seem to mitigate the problem of historical and hermeneutic distanciation on both ends, as it were. For if the frameworks of ancient texts and ideas were not themselves culturally monolithic, then we need not worry about some kind of hypostatized classical "Indian" or "Chinese" cultural tradition that is, in some stereotypical ways, essentially different from that of the interpreter, for the former have their own internal differences and plurality of

Journal of World Philosophies 2 (Summer 2017): 121-143

Copyright (C) 2017 Douglas L. Berger, Hans-Georg Moeller, A. Raghuramaraju, Paul A. Roth.

e-ISSN: 2474-1795 • http://scholarworks.iu.edu/iupjournals/index.php/jwp• doi: 10.2979/jourworlphil.2.1.09 
perspectives. In addition, the interpreter's culture is not some isolated monolith that stands untouched by intercultural exchange, as it has been processes of modern history that have brought ancient traditions in touch with our own in such a way as to have made whatever text an interpreter is working with an object of interest and inquiry to begin with. In this manner, cultural hybridity would seem to erode the premises upon which hermeneutic distanciation rests, and thus frees interpreters to contribute to an ongoing process in which complex perspectives communicate with one another.

But, for all its value and promise, there is a danger in relying too heavily on cultural hybridity while pursuing cross-cultural philosophical inquiry. The danger is that we become too complacent in it. The comfort that can be drawn from the creative but, as it were, already-accomplished facts of hybridity may be tempting, since it does not necessarily challenge our prevailing philosophical frameworks and ways of life. If we are inclined, for example, to simply accept that classical Indian pramana theories may be studied and made relevant to problems extrinsic to their historical development, and shorn in some cases from the ways of life and practice whose justifications they were invented to defend, then we might consider them "tamed" for our own purposes. ${ }^{4}$ If we are disposed to believe that ancient Confucian conceptions of ritual aesthetics or methods of moral reflection can be sufficiently broadened to envelop contemporary demands of socio-political challenges, then will their power to put us in question, rather than answer our pre-conceived questions, be muted?5 Raising these possible conundrums is not intended here to deny that the philosophical questions or moral crises of our times should be irrelevant to us, and that we ought to become antiquarians with the kinds of transparent access to the past that have already been critiqued above. Trying to remove ourselves from these concerns would surely be ill-advised, and more, impossible for all practical purposes. But it does pose the problem of whether or not a nod to cultural hybridity risks drowning out the voices of the ancients with those of our own, and insulates us from the sharp edges of philosophical perspectives whose significant differences from our own could both benefit us and expand our own vision.

Perhaps one difficulty with all the foregoing issues of cross-cultural philosophy, from the legacies of colonialism to hermeneutic distanciation to an all-too-easy hybridity, is the kind of automatic or relatively unconscious influence that they work over our interpretation. We cannot erase the legacies of colonialism by fiat, we exist irrevocably within our historical situation, and cultural hybridity is also an ongoing result of communal and global interaction. We do not, as individual researches bring these things about nor can we prevent them. They are forces that are part, to borrow a Heideggerian term, of our "facticity" and are, in the big picture, not products of our conscious effort. And even when we have made the effort to thematize these problematics and set them before us in a theoretically weighty fashion, might they seem to us to be too weighty, too inescapable or incorrigible, for us to expect too many gains from "comparative" philosophical ventures? Perhaps we might get farther if, in addition to somewhat curbing our expectations of completely overcoming our hermeneutic limitations, we work consciously at every step of the interpretive and critically reflective stages of the process of cross-cultural thought, to push those limitations slightly aside and ourselves slightly forward.

In my own recent institutional work and individual research in cross-cultural philosophy, I have attempted a few different approaches to changing the parameters within which cross-cultural philosophical discussion and reflection takes place. They have been designed to combat at some of the problems discussed here, namely of the legacies of colonialism and hermeneutic distanciation. I do not at all believe that my attempts, as I will admit along the way, completely resolve these problems, but they may enable a degree of hermeneutic expansion while at the same time create a space where we can step outside some of the pitfalls of colonialism's legacies.

Institutionally, as a Board member and former president of the Society of Asian and Comparative Philosophy (USA) in recent years, I have tried when possible to take a different approach to organizing the conference panels. Instead of confining conference panels to individual thinkers, specific time-periods within traditions or broader discussions within traditions, or especially panels that pit one classical Asian thinker against

Journal of World Philosophies 2 (Summer 2017): 121-143

Copyright (C 2017 Douglas L. Berger, Hans-Georg Moeller, A. Raghuramaraju, Paul A. Roth.

e-ISSN: 2474-1795 • http://scholarworks.iu.edu/iupjournals/index.php/jwp• doi: 10.2979/jourworlphil.2.1.09 
one Western philosopher, I thought a different route promising. When it was possible, I arranged panels that created discussions between representatives of different Asian traditions, which created discussions between, for example, Indian and Japanese, Chinese and Korean and Sri Lankan and Vietnamese philosophers. ${ }^{6}$ Of course, Western philosophers were often included in these inter-Asian discussions, but as contributors to a broader dialogue rather than as the thinkers laying down the supposed standards and categories according to which other traditions were measured. Such an approach tends toward the recognition of the truth that there are indeed many forms of thought and life that, on their own and in their engagement with others, are just as powerful and compelling as one's own. It also has the benefit of enabling reflection and discussion to take place within and between assumptions and frameworks outside the intellectual ambit of the West, and so allows for both renewed and creative philosophizing.

I have also taken this tack in my own research in recent years. Having begun my career primarily with work in the Indian and Continental European traditions while dealing with Chinese thought exclusively in the classroom, I turned toward more serious research into classical Chinese thought, and then an extended examination of historical interchange between classical Indian and Chinese heritages. Specifically, after some years immersed in theories of consciousness or awareness in the Indian and Continental contexts, and then dabbling in classical Indian and modern physicalist conceptions of mind, I turned to a major study to transformations in the philosophy of awareness that took place when Buddhism moved from the Indian to the Chinese world. ${ }^{7}$ In the $6^{\text {th }}$ century, an important innovation took place in Vijnánavāda thought as commentaries on the school began to be undertaken in Chinese. This innovation had to do with the Buddhist conception of the "luminosity" of awareness, which was changed from being a feature of the achievement of consummate awakening to a pre-existing condition of a basic level of awareness that had to obtain in order for awakening to take place. This new notion of the already-existing "luminosity" of awareness which awakening recovers rather than discovers had an enormous effect on most East Asian schools of Buddhism and even on some neoConfucian thinkers. Engaging in a philosophical way, and not merely as a matter of intellectual or doctrinal history, with this reformed notion of the "luminosity" of awareness was challenging. Not only does this notion not cohere well with traditional realist or idealist notions of consciousness familiar to Western discourse, but it also presents challenges to thinking about the relationship between awareness and the psycho-physical conditions and capacities of the body and practice that are not much considered in contemporary Western discussions of the philosophy of mind. Indeed, even at the immediate completion of my study, I was and remain not sure of how to philosophically assess the idea of "luminosity" of mind as it relates to the rest of our embodied personhood. However, I still take the challenge to be exceedingly worthwhile. After all, for far too long and to far too great a degree, the standards of Western thought, as noted above, have been considered the measure of ideas from other traditions, and in this case, the optimistic depiction of human beings and their possibilities in knowledge and action that the idea of luminosity implies may serve as valuable philosophical provocation for us in our modern and post-modern predicaments.

I do not pretend to be making the case here that either I or any other cross-cultural philosophy scholar can completely transcend the conditions of being influenced palpably by the legacies of colonialism or the limits of historical and hermeneutic distanciation. We are after all doing our work within our historical contexts, writing, in the present case, in a Western language, and are motivated by concerns quite appropriately relevant to our own time and circumstances. Even when merely trying to present various philosophical ideas and frameworks from sometimes radically different worldviews in modern scholarship, we are presenting them for "target" audiences that also operate within contemporary situations. So, encouraging dialogue between other traditions within a Westernized academic context and encouraging the revival of philosophical conversations that originated outside of the modern Westernized framework does not get us out of all the challenges of "comparative" thought enumerated above. Indeed, it may even be argued that exploring sometimes radically

Journal of World Philosophies 2 (Summer 2017): 121-143 
different classical traditions rather than those of the West actually aggravates historical and hermeneutic distanciation rather than resolving it, and I would concede that this is still a considerable difficulty.

However, these efforts have evolved from a belief that those of us doing work in cross-cultural philosophy must make ongoing conscious and reflective efforts to broaden our hermeneutic and philosophical horizons, rather than merely leaving our methodological considerations fettered in circumstances and forces that are more or less already-formed factual conditions of our inquiry. These efforts may help us to broaden our hermeneutic boundaries and venture farther into the ideas of other cultural traditions, creating possibilities for new avenues in philosophical discourse. Moreover, these efforts may help to transform who we are and how we view the world we live in. Though Paul Riceour, as seen above, pushed back against the notion that all of interpretation is self-projection, he still seemed to envision immersion into a text as an opportunity for the reader to "project himself" into another world of thought. The hermeneutic expansion I have in mind here does not so much empower the interpreter to place herself, as an already-shaped and static thinker, into another context, but instead looks toward how the interpreter and the philosophical conversations she takes up can be reshaped through broadened encounters.

1 Wilhelm Halbfass, a student of the works of Paul Hacker, demonstrated how such processes played out during the 19th century "Bengali Renaissance" and after in modern India; see his (1988: 197-262). One can also see how such themes play out in $20^{\text {th }}$ century Chinese scholarly treatments of the development of their own tradition for instances in Fung Yu Lan's A History of Chinese Philosophy (1973). This trend can also be seen in other prominent $20^{\text {th }}$ century Chinese philosophers such as Mou Zongshan.

2 Again, Gadamer (1994: 296-97) waxed optimistic on this score, arguing that such distance was another pre-condition of the interpretive process, and that the intervening time between a "traditionary" text and an interpreter conferred the "belonging" of a text to the entire history of its reception. However, such a methodological "privileging" of the modern interpreter as an inheritor of an entire tradition to which the authors of a "traditionary" text did not have access seems too easy a finesse for how different the conditions and historical demands of authors and interpreters of much later times, who belong to quite different traditions, may be.

3 Excellent examples of pointing out pluralistic approaches to interpretation in classical traditions and seeing modern readings as a continuation of such trends can be located especially in modern scholarship on Confucianism. See, for instances Ivanhoe (2002), and Tan (2014).

$4 \quad$ See Mohanty (1993: 207-10).

$5 \quad$ In his classic and still important Tanner Lectures (collected in 1991), William Theodore de Bary points out that, while the fundamental concern implanted within Confucianism from its inception with the ideal form of government will ensure its continued relevance, the historical meaning of the aphorisms found in the received Analects have "almost nothing" to do with us in the contemporary world (de Bary 1991: xiii). What I wish to suggest here is that the radical difference of classical texts, and not just how they might be applied to our own circumstances, should remain philosophically important to us.

6 I have with this approach attempted a practical realization of what is described by Ram Adhar Mall is an intercultural philosophy that does not employ one standard of philosophy to adjudicate the thought of other cultures, but instead to put those standards and traditions directly into dialogue with one another; see his "Intercultural Philosophy: A Conceptual Clarification" (2014: 80-3).

$7 \quad$ See Berger (2015).

Journal of World Philosophies 2 (Summer 2017): 121-143 


\title{
Remarks on the Paradox and the Unmarked Space of Cross-Cultural Philosophy
}

\author{
HANS-GEORG MOELLER \\ University of Macau, Macau, SAR, China (HMoeller@umac.mo)
}

\section{On Cross-Cultural Philosophy as the Unfolding and Invisibilization of a Paradox}

In order to provide a framework for his plea for a "hermeneutic expansion" of cross-cultural philosophy, Douglas Berger presents a very useful sketch of the history of cross-cultural philosophy and its current predicaments. In this response to Berger's paper, I primarily intend to comment on his analyses of the past and present states of our field (which alternatively has been labeled comparative philosophy or intercultural philosophy, to name only two other designations indicating roughly the same sub-discipline in academic philosophy). Thus, I will only indirectly address the question if it is in need of a hermeneutic expansion, as Berger believes. Instead of discussing such a potential need, I will, in the second part of my contribution, point to a somewhat forgotten task that the field might want to consider taking up before eventually moving forward towards new hermeneutic horizons.

At the outset of his deliberations, Berger rightly points out two "fundamental difficulties" that have been plaguing cross-cultural philosophy since its inception. The first of these fundamental difficulties is directly tied to the field's historical origins; as Berger says, "it has grown out of colonial contexts" (Berger 2017a). (I am not sure if by using the expression "has grown out of" Berger meant to say that it not only developed along with colonialism but also that it left its colonialist heritage behind for good.) As it is well known, a serious intellectual interest in non-Western thought and texts, which could be classified as philosophical, emerged in the West along with the increasing integration of non-European civilizations into an emerging world society in the context of the socio-political process called Colonialism. "Orientalists" thus paved the way for cross-cultural philosophy. Their descriptions and categorizations of foreign societies, foreign morals, foreign religions, and foreign ideas suggested to modern philosophers that they needed to assign a place to the excluded "other" if they wished to think truly universally and thereby all-inclusive. The paradoxical beginning of modern crosscultural philosophy thus consisted in the endeavor to include an excluded moment into the complex operations of the "world spirit" (to speak in Hegelian terms).

Speaking with the German social systems theorist Niklas Luhmann who tends to describe the overall development of modern society in terms of a productive "unfolding" (Paradoxieentfaltung) and "invisibilization" of various paradoxes, the history of cross-cultural philosophy could well be described as the institutionalized communication effort resulting from the paradoxical distinction between universal rationality and newly discovered alternatives to it, and the subsequent "re-entry" (in Luhmann's technical terminology) of this distinction into the further unfolding of rationality in the form of a distinction between "our" and "other" ways of thinking. (This re-entry took place on one side of the distinction, namely on "our" side of universal rationality.) This would mean that cross-cultural philosophy not only owes its existence to the making of a paradoxical distinction, but also that its future lies in the persistent need, resulting from the emergence of the paradox, to invisibilize it in one way or another. Put differently, this mechanism can also be described as the "hermeneutic circle" identified by Berger as the second fundamental difficulty of cross-cultural philosophy,

Journal of World Philosophies 2 (Summer 2017): 121-143

Copyright (C 2017 Douglas L. Berger, Hans-Georg Moeller, A. Raghuramaraju, Paul A. Roth.

e-ISSN: 2474-1795 • http://scholarworks.iu.edu/iupjournals/index.php/jwp• doi: 10.2979/jourworlphil.2.1.09 
namely the need to explain the "other" in "our own" terms in order to make sense of it. This need entails a potential problem: Once we have fully understood the other in this way, we have also paradoxically reduced its otherness to zero. Or, alternatively, if we have succeeded in establishing the actual otherness of the other, we have thereby effectively invalidated our own ability to assess it. Such a hermeneutic circle may seem a menace, but from a pragmatic perspective grounded in contemporary social systems theory, it could also be regarded as the very condition of the possibility of cross-cultural philosophy. In other words, the circle does not necessarily have to be seen as inherently vicious, but can also be conceived of as a foundational blessing (albeit a mixed one) upon which the professional lot of cross-cultural philosophers depends. Cross-cultural philosophy only has to make sure that the circle is never fully closed, i.e. it has to be careful to neither make the other disappear altogether nor to concede its absolute otherness.

Seen in the light of the foundational paradox of cross-cultural philosophy and its unfolding, the perennial debate between universalists and cultural relativists in cross-cultural philosophy only reflects the two basic options for invisibilization efforts open to participants in this type of communication. One can either work towards minimizing or maximizing otherness in order to cover up the paradox that begets the effort to familiarize oneself with the unfamiliar by recognizing its unfamiliarity. Historically, the minimization camp has, among other candidates, tried out logic (G.W. Leibniz), God (e.g. missionary-sinologists such as James Legge), human rights or a universal ethics (Heiner Roetz), and, more recently, cognitive science (Edward Slingerland) as potential paradox "invisibilators."

The maximization camp, on the other hand, has spilled a lot of ink trying to determine how we should position ourselves towards the other (which, it should be added, always appears in a different shape, depending on how "we" determine it). Some concluded that we should best understand it negatively as lacking most of what constitutes "us" and formulated, to use a German (and thus rather awkward) term coined by Heiner Roetz, Defizienzipostulate (deficiency postulates). G.W.F. Hegel, and, to a certain extent, Marcel Granet (but also, on a much smaller scale, the "Bonner Schule" of Sinology founded by my teacher Rolf Trauzettel) could be named as representatives of this approach. Others, however, wanted to conceive of the other positively as containing and offering something that "we" lack. As a consequence, the deficiency postulates point in the opposite direction. Roger Ames and Henry Rosemont Jr., for instance, stipulated that Chinese philosophy has established a sense of communality and a refined role ethics that as such has been unknown to "us;" and they therefore encourage us to adopt it in order to correct certain shortcomings (such as a philosophically inadequate and morally harmful individualist worldview). Here, the focus on the exceptional merits of the other moves the foundational paradox of cross-cultural philosophy into the background. A variation of the focus on the unique value of the other can be found in the works of Francois Jullien. Jullien succeeds in embellishing the aesthetic appeal of the other so that it evokes a considerable fascination which is strong enough to obliterate its paradoxicality.

From a social systems theoretical perspective, the communicational functionality of all these forms of cross-cultural philosophy can be acknowledged or even celebrated: they all make sense. From this theoretical point of view, making sense is a constructive achievement. Sense, in this sense, is not made as a cognitive illumination of a presumably given "thing in itself" (such as, e.g. "Chinese Philosophy" or "Chinese Thought"), but rather as an effect of functioning communication which operates in a specific social context and is capable of generating further communication of the same kind. Simply put, cross-cultural philosophy is not contingent upon "cross-culture" but, just like any other philosophy, contingent upon philosophy as a field of communication within the academic system of society. Douglas Berger, too, seems to indicate this when he writes that "the variously inflected secular trends of professional academic research $[\ldots]$ facilitate much of what we take to be philosophical writing, teaching and interchange today."

As contributions to the productive unfolding of a foundational paradox, the various communicative strategies of cross-cultural philosophy outlined only very briefly above have all proven their respective

Journal of World Philosophies 2 (Summer 2017): 121-143

Copyright (C) 2017 Douglas L. Berger, Hans-Georg Moeller, A. Raghuramaraju, Paul A. Roth.

e-ISSN: 2474-1795 • http://scholarworks.iu.edu/iupjournals/index.php/jwp• doi: 10.2979/jourworlphil.2.1.09 
"connectivity;" they allowed for meaningful academic discourses and professional careers to take shape. The field is still growing on this basis as shown by the emergence of new academic publication outlets, such as the journal in which this short paper will be published. We can only hope, as noted above, that neither the maximization nor the minimization efforts lead to a final consensus that would threaten the future existence of the field.

\section{On the Unmarked Space of Cross-Cultural Philosophy: The Other Paradox}

Given its dependence and focus on the "other," it is perhaps quite astonishing that hermeneutic as well as historical reflections on cross-cultural philosophy often largely ignore the "other half" of cross-cultural philosophy, namely the one not done in the West, but in the non-West. While cross-cultural philosophy has been a rather benign and sometimes close to non-existing sub-discipline within academic philosophy in Europe and North America throughout most of modern history, it has been at the center of the philosophical activity in many non-Western countries and regions, such as China, which is the only "other culture" that I can claim some competence in. In China, most of the modern philosophical discourse has been cross-cultural. This discourse emerged around the turn from the $19^{\text {th }}$ to the $20^{\text {th }}$ century in the context of a large-scale adoption of originally "Western" social structures and semantics, including institutionalized academia and the language and canons of its disciplines. This adoption necessitated the re-interpretation of parts of the traditional Chinese "classics" (jing 经) and/or "masters" (zi 子) in terms of (Western) philosophy. A main effort of academic philosophy in China consisted in applying the historical frameworks and conceptual apparatus of Western "philosophy" (translated into Chinese as zhexue 哲学) in China and to Chinese texts. ${ }^{1}$ The re-writing of Chinese philosophy in a cross-cultural context, however, was not confined to the import of Western philosophy and the simultaneous integration of Chinese traditional works into a new academic discipline, but also included the creation of a new Chinese cross-cultural philosophy aimed at synthesizing the Western and Chinese traditions into a new world philosophy. The great philosophical systems developed by Xiong Shili (熊十力, 1885-1968), Feng Youlan (冯友兰, 1895-1990), and Mou Zongsan (牟宗三, 1909-1995), to name just a few major thinkers, are representative of this trend.

Despite the essentially cross-cultural nature of modern Chinese philosophy, its contents, methods, and hermeneutic struggles have hardly concerned the discourse of Western cross-cultural philosophers sketched above. It seems that the unfolding and invisibilization of its own inherent paradox preoccupied Western-based cross-cultural philosophy so much that not much time could be spared for cross-cultural approaches to crosscultural philosophy_and thus the Eastern cross-cultural philosophy that evolved at the same time tended to remain a more or less "unmarked space" for its Western counterpart, to speak once more in Luhmannian terms. In the East, however, due to the general situation just depicted, cross-cultural philosophy had been a crosscultural endeavor from the start.

The most comprehensive account of the history of Asian cross-cultural thought that I know was not written by a professional academic but by a professional writer; it is From the Ruins of the Empire: The Intellectuals Who Remade Asia by Pankaj Mishra (Mishra 2012). In this book, Mishra skillfully narrates numerous life stories of $20^{\text {th }}$ century intellectuals and social activists (as one might say today) from the Near and Far East who tried in different ways to redefine their and their nation's or culture's political, religious, and, in a wider sense, philosophical identity. The paradox that emerges over and over again in Mishra's book is different from the one outlined in the first part of this paper, but mirrors it in an inverted form. Asian cross-cultural discourses tend to emerge from making a distinction between an (Eastern) identity regarded as one's own and an alien

Journal of World Philosophies 2 (Summer 2017): 121-143

Copyright @ 2017 Douglas L. Berger, Hans-Georg Moeller, A. Raghuramaraju, Paul A. Roth.

e-ISSN: 2474-1795 • http://scholarworks.iu.edu/iupjournals/index.php/jwp• doi: 10.2979/jourworlphil.2.1.09 
(Western) one which, in the context of colonialism, has replaced, overshadowed or weakened the former. The emerging paradox, which is unfolded and invisibilized in various shapes and forms, is, in short, that one's own "true" identity is discovered and understood only in terms of a "false" or alien identity. The distinction between one's own and an alien identity re-enters the distinction on the side of the alien identity. This, at least, would be a way to outline the communicative structure of some non-Western cross-cultural discourses from a social systems theoretical perspective. To further reflect on this other paradox may be a way to extend cross-cultural philosophy cross-culturally.

$1 \quad$ On details of this process see: Makeham (2012). 


\title{
Consolidation before Expansion: Revisiting Cross-Cultural Philosophy
}

\author{
A. Raghuramaraju \\ Department of Philosophy, University of Hyderabad, India (raghurama9@gmail.com)
}

Douglas L. Berger's anchor essay, "Cross-Cultural Philosophy and Hermeneutic Expansion," makes a serious attempt to extend the scope of cross-cultural philosophy. My response, which is in four parts, aims to take the discussion further by showing that it is really a deepening and consolidation of cross-cultural philosophy that is needed rather than expansion. In the first part, on the theme of the symposium, "Does cross-cultural philosophy stand in need of a hermeneutic expansion?" I will closely scrutinize the need for hermeneutic expansion of cross-cultural philosophy by bringing into the discussion another form of expansion, namely, horizontal expansion. The second part moves inside Berger's essay. I will show how the links between the claims made by him, in the context of making a case for the hermeneutic expansion, are not very strong. The next part while accounting for the difficulties arising out of cross-cultural comparison suggests the need for scrutinizing the problems that arise when Western philosophers ${ }^{1}$ compare modern Western philosophy with traditional Western philosophy. While the first part of my response concentrates on the title of the symposium and the next two parts move inside Berger's essay, the last one discusses issues that concern cross-cultural philosophy, but are not covered in the essay.

At the outset let me clarify the nature and extent of the theme by pointing out that the symposium seeks to explore and find out whether there is a need to expand the horizons of cross-cultural philosophy. This I take as the larger concern of the symposium. The symposium focuses on one form of expansion, namely hermeneutical expansion of cross-cultural philosophy. This clarification is necessary, I believe, as there may be other kinds of expansions that one might explore with the aim of extending the horizons of cross-cultural philosophy. For instance, there may be horizontal expansions. The horizontal, like the hermeneutical, need not merely extend Western philosophy to include the non-Western, for instance, Chinese or Indian philosophy. The expansion can also be an extension of the horizons of a part within Western philosophy, for instance, Anglo-Saxon, modern, Western philosophy may include another part, namely, modern, Western, Continental philosophy referred to by Berger.

The reason why I raise this point right at the beginning is that it allows us to avoid thinking of the West as 'us' and the non-West or the East or Asian as 'them.' It permits us instead to disaggregate the 'us' into different parts, each one not necessarily in equilibrium or in harmony with the other. Alternatively, 'culture' need not only mean Eastern and Western as is assumed by those who inhabit this terrain but also include different cultures within both West and East. I will confine myself to the cultures within the West. In this way, we are able to see that what Berger rightly highlights about cross-cultural philosophy can also applies to one of its parts, the major one at that, namely, Western philosophy. Let me elaborate.

In making a case for the need to offer hermeneutical expansion to cross-cultural philosophy, Berger rightly points out that this discipline is not governed by 'a priori' principles as it is not possible to know in advance what sort of "resonances," "differences," or "conversations" can take place in this dialogue. He further adds to this unpredictable and volatile nature of the discipline another feature when he points out that we do not know beforehand "what sort of methodological approaches will be appropriate to conducting cross-cultural

Journal of World Philosophies 2 (Summer 2017): 121-143

Copyright (C 2017 Douglas L. Berger, Hans-Georg Moeller, A. Raghuramaraju, Paul A. Roth.

e-ISSN: 2474-1795 • http://scholarworks.iu.edu/iupjournals/index.php/jwp• doi: 10.2979/jourworlphil.2.1.09 
conversation." Given the absence of both a priori principles and methodology he concludes that the "best approaches emerge from the process and the experiences drawn from it." This consists of both "individual researches and cultures" that produce an activity "in which certain lessons may be learned through the course of time." Then he moves on to address the theme of the symposium by saying, "where do we stand after recent centuries of cross-cultural philosophical engagements between various Western and Asian traditions, and should such a stock-taking provoke us to alter approaches that have been employed so far?”

Let me make two points here. One, while agreeing with Berger about there being no a priori principles and methodology, it is necessary to ask whether what he says about cross-cultural philosophy is also equally applicable, at least in some situations, to Anglo-Saxon and Continental philosophies. One can ask the question whether there are a priori principles and a methodology applicable to the discussion between the two subdisciplines belonging to each tradition, or between cultures belonging to different geographical regions within the West. Take for instance, Berger's example. He claims that the Buddhist idea of "luminosity" does "not cohere well with traditional realist or idealist notions of consciousness familiar to Western discourse." This he says poses a challenge to "thinking about the relationship between awareness and the psycho-physical conditions and the capacity of the body and practice that are not much considered in contemporary Western discussions of the philosophy of mind." Granting that there is a challenge, one might argue that it is equally challenging to attempt to use a philosophical idea from either Gadamer or Ricoeur in the context of a discussion of philosophy of language or mind. There is no ready-made a priori principle or methodology in place. The famous debate between Searle and Derrida on the theme, structure of language and how language interacts with people, offers at least a partial example in support of this claim.

I raise this point here to highlight the unevenness and rough edges within the practice of Western philosophy and to move the discussion away from the terrain of cross-cultural philosophy towards the philosophical practices within the West. This unevenness will also impact upon the continued use of the term "Western philosophy," although I will not be able to deal with this aspect within the scope of this response. For the sake of analysis, however, I will continue to use this term in the following pages. I request the reader to bear in mind though that there are rough edges in comparing one system with other. The heterogeneity of the term 'West' does not give us a monolithic entity that can be freely used in cross-cultural comparison. ${ }^{2}$

I aim to show that some of the problems that surround cross-cultural philosophy are actually reflections of one of its own parts, namely Western philosophy. In their cross-cultural inquiry, its proponents tend to construe a homogenous entity called the 'West,' thus blurring its uneven boundaries in the process. Here I am making the claim that these problems are not present either in Indian or other Asian philosophies. So, the nature of Western philosophy has to be factored in before one may begin to explore the border between the West and the non-Western philosophies. There is a distinctly positive note here in that the inputs from this horizontal expansion, from Anglo-Saxon to Continental philosophy, where at least colonialism is absent, can be used to extend the horizons of cross-cultural philosophy. So, there is a close relation between horizontal and hermeneutic expansion as the former can reflect and enrich the latter.

My next point is that if there are no a priori principles and methodology that render the situation unpredictable, where everything is left to the individual researcher and culture, what is necessary is the re-examination and reformulation of existing procedures, principles, and methodologies to free them from any traces of narrowness or partisanship. Only then should follow their consolidation and strengthening. So, extension may not be an appropriate thing to do unless Berger uses the absence of ready-made approaches in a positive sense and wants to retain the freedom and fluidity that they signify.

Journal of World Philosophies 2 (Summer 2017): 121-143

Copyright (C 2017 Douglas L. Berger, Hans-Georg Moeller, A. Raghuramaraju, Paul A. Roth.

e-ISSN: 2474-1795 • http://scholarworks.iu.edu/iupjournals/index.php/jwp• doi: 10.2979/jourworlphil.2.1.09 
Having pointed out the underlying relation between the horizontal and the hermeneutic, let me discuss the need, according Berger, for broadening the horizons of cross-cultural philosophy. Though he does not critically discuss the need for such broadening, which is taken by him as necessary, he does highlight the difficulties with regard to existing cross-cultural philosophies. Let me discuss these difficulties.

The first difficulty with regard to comparative philosophy practiced in the past "five hundred years" is that one of the parts of the subject of comparison, namely the non-West, has been colonized by the other part, namely, the West. In the process, a homogenous "non-West" is construed, which is defined as the complete opposite of the West. This historical and political reality, where the "European and American military and economic powers" colonized Asian societies and produced unevenness, had a deep impact on the transmission and representation of Asian knowledge systems. For instance, says Berger, "Western philosophies, despite their historically provincial frameworks and categories, were erected as the standards for universal thought and truth." Having encroached into the universal from the provincial, they dismissed local traditions as unphilosophical or proceeded to measure them against Western standards like objectivity, rationality, universality. Even when there were no dismissals based on unreasonable evaluations and attempts were made to look at other philosophical traditions at a philosophical level, there arose another theoretical problem: namely, the inevitable problem of "prejudice." As crisply expressed by Berger, the problem occurs because when we look at the other tradition, we not only look as ourselves, but often also look for ourselves in them. This asymmetry, that is accompanied by the political context of colonialism, interferes with West's philosophical activity, rendering a non-prejudiced understanding of the "other" difficult, if not impossible. While conceding that it is "not easy" to escape this trap, Berger still contends that there is a need for the West to "strive for transcending, an escape, from our historical and hermeneutic situatedness in an attempt to arrive at some abstracted 'neutral' stance in comparative studies." In this context, he makes a fervent plea that defies paraphrasing, when he says,

Are there ways we may be able to, not so much break out of the 'hermeneutic circle' or pretend that we are not heavily influenced by the legacies of colonialism, but perhaps expand our hermeneutic boundaries instead, and forge overlappings with other 'circles' of thought, creating new relationships between cultures? (Berger 2017a)

Having raised these difficulties to break out of hermeneutic circle, he confesses that "growing up in any modernized cultural tradition and being trained from within a westernized academic system hardly makes anyone, practically anywhere, immune from either the legacies of colonialism or hermeneutic distance." This predicament, he admits, where one is faced by "historical distance" is a "potential barrier for the scholar." He goes on to admit the extent of this barrier. For him, the extent includes not only doing "cross-cultural thought" but also "investigating the ancient texts of a tradition that is supposedly their "own."

Taking up this point and changing its focus slightly, I would suggest that before embarking on the difficult task of extending the boundaries of cross-cultural philosophies, it would be extremely meaningful to examine the problems that arise when philosophers trained in modern Western philosophy interpret or try to understand the classical philosophies of their own tradition. Examples here would be Gadamer's work on Plato and Aristotle, and Alasdair MacIntyre's use of Aristotle. When we critically scrutinize their work, one factor gets neutralized, that is, colonialism is absent when the native moderns access their own tradition. This is

Journal of World Philosophies 2 (Summer 2017): 121-143 
important because it is this factor, according to Berger, that has contributed to the difficulties in reducing the prejudice.

Alternatively, instead of using the insights from Gadamer and Ricoeur to understand the cross-cultural, we could use them to understand the nature of the prejudice that arises when one's own tradition is being dealt with. One can closely scrutinize whether there is unevenness or enrichment, in the comparison even when two philosophical schools within the West are compared. If there is unevenness, then we have to attend to this before we undertake the task of correcting the comparative axis in cross-cultural philosophy. If enrichment, is it of the self or the other or the inside or the outside? On the assumption that there will be less prejudice in this engagement, one may then turn to other cultures, by adding to or deleting the experience from within.

The exercise is important as there is no colonial context for the comparison between modern and traditional Western philosophy. Studying the problems that arise between any comparisons, for instance, comparing traditional and modern philosophies might provide a better understanding to study the problems arising out of studying cross-cultural philosophy. That is, there is a need to distinguish between specific problems arising out of comparison in cross-cultural philosophy and the comparison between traditional and modern Western philosophies. The reason why I explored this line of thinking is to disaggregate imbalances and injustice by focussing on internal imbalances and injustices. I also want to refrain from equating imbalances and injustice with the East in comparative philosophy.

Having made two critical comments about Berger's essay, let me in this last part point out some issues that surround cross-cultural philosophy that should be factored in before embarking on extending the boundaries of this discipline. There have been many attempts to compare and contrast Western and Eastern philosophies. Many of them are covered by Wilhelm Halbfass referred to by Berger. In this context, there is a need to look closely at the details of the 'past five hundred years' especially in the East-West conference initiated by Charles A. Moore in 1939 to forge a comparative philosophy between East and West. The 1984 conference on the theme, 'Interpreting Across Boundaries,' points out that the "various volumes that have emerged" from the previous "East-West philosophers' conferences" or the "back issues of the journal Philosophy East and West" promoted the "tendency to favour similarities in comparative work while ignoring or glossing over differences" (Larson 1988: 9). The 1984 East-West conference instead began to highlight differences between Eastern and Western philosophies. Daya Krishna in his paper presented in this conference points out the unevenness in the comparative access where he alleges, "the so-called comparative studies were primarily a search for facts or a reporting of data in terms of conceptual structures already formulated in the West" (Krishna 1988: 73). This is an important criticism. In turn, I have pointed out how the comparison undertaken by those like Daya Krishna, B. K. Matilal created a temporary imbalance as these scholars sought to compare classical Indian philosophy with modern Western philosophy. This form of imbalance, where classical Indian philosophy is compared with modern Western philosophy, the former, given its archaic nature, is placed in a position of disadvantage thus becoming vulnerable to lose in the comparison. When a modern Western philosophy is compared with classical Indian philosophy as undertaken by Matilal in his comparison of Nyaya with analytical philosophy, or Daya Krishna and others who propose Samvad where traditional Pundits are in dialogue with modern Western logicians, Indian philosophers defending classical theories are rendered vulnerable (Raghuramaraju 2006). I have brought these details into the discussion in order to take stock of what has already been done in the field of cross-cultural philosophy.

In making these four points what I want to do is to thicken the plot deftly laid down by Berger and to take the discussion further.

Journal of World Philosophies 2 (Summer 2017): 121-143

Copyright (c 2017 Douglas L. Berger, Hans-Georg Moeller, A. Raghuramaraju, Paul A. Roth.

e-ISSN: 2474-1795 • http://scholarworks.iu.edu/iupjournals/index.php/jwp• doi: 10.2979/jourworlphil.2.1.09 
1 It is another matter that I have in my paper "Rethinking the West," identified the recent origin of the term West. See Raghuramaraju (2005).

2 Incidentally, the East-West conference held in 1984 recognized this issue and debated upon it. 


\title{
Translation and Understanding: What the Problems Are Not
}

\section{PAul A. Roth}

\author{
Department of Philosophy, University of California-Santa Cruz, USA (paroth@ucsc.edu)
}

For at least 50 years an active conversation has transpired in and out of philosophy on the topic of translation and understanding, both with regard to natural languages as spoken by native speakers to one another and with regard to intercultural cases. The roles of cultural and temporal distance, and especially of authorial positioning, have received what can only be described as relentless and detailed analyses.

Dating takes on a semi-arbitrary aspect in this regard. But certainly classics in the area include Peter Winch's "Understanding a Primitive Society," (1964) and the extensive literature that arose in response, especially as collected in Bryan Wilson's canonical anthology Rationality (1970). That debate drew its inspiration from Winch's reading of the later Wittgenstein, but Wittgenstein hardly stands alone in having inspired these discussions. Clifford Geertz's ethnographic work exerted wide appeal within and without anthropology, dating at least from his extremely influential collection of his essays, The Interpretation of Cultures (1973). His later thought reflects on how the backgrounds of various ethnographers influenced their practice, but especially $W$ orks and Lives: The Anthropologist As Author (1988).

Geertz's writings and his stature notoriously led to an entire movement devoted to analyzing the "ethnographer as author," complete with worries about colonial and post-colonial influences. The volume edited by James Clifford and George Marcus, Writing Culture: The Poetics and Politics of Ethnography (1986) constitutes a signature collection here and represents an important (and in many respects ongoing) debate with cultural anthropology and philosophy of social sciences. (See especially Marshall Sahlins How "Natives" Think and his extended exchanges with Gananath Obeyesekere on the Hawaiian Islanders and Captain Cook).

Within mainstream philosophy you have Quine writing on the "indeterminacy of translation," (e.g., Word and Object, 1960) and Donald Davidson's widely known and much discussed "On the Very Idea of a Conceptual Scheme" (1973). Writing in the tradition of phenomenology and critical theory, one finds major works by Charles Taylor, James Bohman, and Anthony Appiah on understanding and multiculturalism. All of this would seem directly relevant to issues raised by Douglas Berger. None of the literature just noted receives any mention or acknowledgment by him.

But of course, in a relatively brief essay one can only do so much, and it would in ordinary circumstances serve no good purpose just to cite those works someone omits. However, the omissions here prove symptomatic of far more significant concerns regarding the philosophical presuppositions in Berger's essay. Berger claims to identify "two fundamental problems" (Berger 2017a) with regard to working in crosscultural philosophy. One involves the intellectual and economic legacies of colonialism, positionings that resulted in cases where "the philosophical traditions they confronted were often measured against Western standards or dismissed as "unphilosophical"' (ibid.). Note that these are exactly the issues discussed in almost all the works cited above.

Berger's second problem he terms that of "hermeneutic prejudice," one he appropriately connects to the general issue raised by the hermeneutic circle. " $\Pi \mathrm{f}$ we are bound, as the historical beings we are, to encounter other traditions at first through our own tradition's language, conceptual framework and civilizational prejudices, then the likelihood of completely abandoning these in the attempt to 'understand' another cultural tradition has but dim prospects [...]. When we look at other traditions, we not only look as ourselves, but often for ourselves in them" (ibid.) The worry that one "translates" relative to one's home language proves to be precisely the sort of point worried by Quine and Davidson about translation (even between native speakers

Journal of World Philosophies 2 (Summer 2017): 121-143

Copyright (C) 2017 Douglas L. Berger, Hans-Georg Moeller, A. Raghuramaraju, Paul A. Roth.

e-ISSN: 2474-1795 • http://scholarworks.iu.edu/iupjournals/index.php/jwp• doi: 10.2979/jourworlphil.2.1.09 
talking to one another), and examined in both theoretical and practical cases by all the others mentioned in my opening paragraphs.

Berger's first concern raises the specter of an unaccommodating cultural imperialism; the second worries about unwitting authorial projections. But the two share a common root, viz., concerns about what sets conditions for meaningful discourse. In brief, then, a puzzle as to how meaning gets constituted represents the core question. But what type of problem is this? Given that no translator can hope to jump out of her cultural and historical skin when confronting the sort of issues that Berger describes, how best then to think methodologically and philosophically about the nature of translation and understanding, i.e., meaning?

Let me begin by rehearsing Davidson's famous complaint from "The Very Idea" essay. There Davidson notes that a number of authors make claims about the foreignness or "untranslatability" of the thought of another time or another culture, and yet proceed to produce without blushing accounts of such. Consider in this regard what Berger writes regarding his own research.

In the $6^{\text {th }}$ century, an important innovation took place in Vijnānavāda thought as commentaries on the school began to be undertaken in Chinese. This innovation had to do with the Buddhist conception of the 'luminosity' of awareness, which was changed from being a feature of the achievement of consummate awakening to a pre-existing condition of a basic level of awareness that had to obtain in order for awakening to take place. This new notion of the already-existing 'luminosity' of awareness which awakening recovers rather than discovers had an enormous effect on most East Asian schools of Buddhism and even on some neo-Confucian thinkers. Engaging in a philosophical way, and not merely as a matter of intellectual or doctrinal history, with this reformed notion of the 'luminosity' of awareness was challenging. Not only does this notion not cohere well with traditional realist or idealist notions of consciousness familiar to Western discourse, but it also presents challenges to thinking about the relationship between awareness and the psycho-physical conditions and capacities of the body and practice that are not much considered in contemporary Western discussions of the philosophy of mind. Indeed, even at the immediate completion of my study, I was and remain not sure of how to philosophically assess the idea of 'luminosity' of mind as it relates to the rest of our embodied personhood. However, I still take the challenge to be exceedingly worthwhile (Berger 2017a).

I have no reason to doubt Berger's standing as a scholar or anything that he says about Chinese or Indian thought. I simply observe in a Davidsonian spirit how ironic his own practice appears in light of his two "fundamental" questions. He writes with authority about philosophical notions originating some 1400 years ago in cultures and languages quite different than our own. Yet his only expressed reservation concerns how these notions can inform on or match up with contemporary debates in philosophy of mind or with regard to realism and idealism. But how then should one square Berger's practice and his worries? The remarks quoted above suggest that his practice trumps his questions. But given his questions, how can his practice be possible? Call this "Berger's paradox."

As I read Davidson, we have no choice but to be "impositionists" with regard to how to "translate" others. This can be done without doubt with greater or lesser sensitivity to time and context. But as Berger's paradox suggests, no magic method exists, no set recipe can be offered. Equally importantly, note the lesson Davidson draws in his penultimate paragraph. "It would be wrong to summarize by saying we have shown how communication is possible between people who have different schemes, a way that works without need of what there cannot be, namely a neutral ground, or a common coordinate system. For we have found no intelligible basis on which it can be said that schemes are different. It would be equally wrong to announce the glorious news that all mankind - all speakers of language at least_share a common scheme and ontology. For if we cannot intelligibly say that schemes 
are different, neither can we intelligibly say that they are one" (emphasis mine). Davidson's "take home" moral, at least as I read him, involves the fact that there exist no fixed points with regarding what constitutes meaning.

Philosophically, I unpack this in the following way. The actual practice of translation, as in Berger's own case, puts into questions claims of ineffable alienness of the thought of others (or Others). Yet one would also be mistaken as well to imagine that some meaning exists in advance of translation. Belief that meaning does so exist represents what I like to term a Kantian hangover from which philosophy still suffers (see, e.g., Chomsky). Those still in the grip of that view imagine the human mind as pre-stocked with fixed categories. But what empirical reason exists for assuming that even those with whom you converse daily "share" in all important semantic and syntactic details the language that you take yourself to speak? Why assume that language exists in advance or apart from efforts from infancy onward to have speakers conform to certain norms, norms that grammar books and dictionaries imperfectly attempt to canonize and educational systems in their own Foucaldian way attempt to impose? Language exists only as a "social construction," just like books on manners or theoretical physics. Everyday experience repeatedly reveals ways in which presumed agreements turn out to diverge due to unforeseen and unanticipated differences in understanding of terms. Belief in a shared language is one more cultural myth with which we live.

The practical problems of translation and understanding doubtless increase as the bases for shared interactions and so correction and adjustment diminish or disappear. But the relevant philosophical and methodological lesson remains the same. Understanding can come to no more than contingent agreement about what appears settled at that moment. Time can and often does unravel confidence that understanding in fact existed. But this does not mean one failed to "get inside the head" of those with whom one converses, either in the moment or with (to borrow Ian Hacking's phrase) "pen-pals from the past." Nothing in the head exists that determines what anyone's words mean. That is the great illusion against which Wittgenstein et al. attempt to warn. There exist only ongoing, holistic attempts to make the best sense we can of ourselves and others. Imagining that some "key" to meaning lies just beyond our reach, locked away in the mind of a speaker or writer may serve as solace for those with an unrequited longing for certainty. But no good evidence exists for determinacy of meaning, and questions of translation and understanding will only be hindered and not helped by any such assumption. As Berger's paradox and ordinary conversation indicate, translation proves ongoing.

Journal of World Philosophies 2 (Summer 2017): 121-143

Copyright @ 2017 Douglas L. Berger, Hans-Georg Moeller, A. Raghuramaraju, Paul A. Roth.

e-ISSN: 2474-1795 • http://scholarworks.iu.edu/iupjournals/index.php/jwp• doi: 10.2979/jourworlphil.2.1.09 


\title{
Symposium Response
}

\author{
DOUGLAS L. BERGER \\ Southern Illinois University Carbondale, USA (dberger@siu.edu)
}

I would like to warmly thank Professors Moeller, Raghuramaraju and Roth for engaging with my initial submission. They have all raised extremely relevant points as well as critical questions to the case I have tried to make for "hermeneutic expansion" in my original piece. I am grateful for their insights and willingness to push the conversation forward.

Professor Moeller skillfully and eloquently identifies a fundamental paradox in cross-cultural philosophy, namely that, in trying to understand the "other," one either tries to "reduce its otherness to zero" in appropriating it into one's own framework or accentuate otherness so much that it becomes inaccessible (Moeller 2017). This paradox can, Moeller helpfully points out, be creative, and can serve as a starting-point for ongoing, dynamic communication between traditions and cultures of all sorts. He goes on to demonstrate, referring to twentieth century Chinese philosophers as well as the monograph by Pankaj Mishra (2012), that thinkers from South and East Asia have been reconstructing their own traditions and re-constituting their own identities vigorously in recent centuries, and in its hermeneutic self-preoccupation, Western comparativists have not paid too much heed to those conversations. I certainly agree with Moeller's points and believe such developments have been at the forefront of societies impacted by the legacies of Western colonialism all over the world, and certainly across all of South and East Asia, and that they would make excellent opportunities to reengage the "communicative structures" of global philosophy. I personally find some of the most fascinating and fruitful endeavors in these reconstructions to have been undertaken in the works of $20^{\text {th }}$ century women philosophers from South and East Asia. Works that have been made available in English of Japanese thinkers such as Yosano Akiko and Hiratsuka Raichō in the scholarship of Michiko Yusa or Korean thinkers such as Kim Irōp in the translation and commentary of Jin Y. Park represent rich and vital explorations of the reconfiguration of traditions in the contemporary world.

Professor Raghuramaraju's paper is most insightful and raises some important questions that I'd like to respond to for the purposes of clarifying my views. First, he strikes a contrast between Anglo-Saxon and Continental traditions of philosophy which, though they are themselves internally heterogeneous, tend to totalize "Western philosophy" when they engage cross-cultural thought, while such totalization is not present in, for instance, the Indian tradition. This point helps us focus on the fact that the discourse I take up as a participant in cross-cultural philosophy is itself a Western discourse. Perhaps, he suggests, the internal interchange between Anglo-Saxon and Continental traditions, "where colonialism is absent," can itself also serve as a site of hermeneutic expansion (Raghuramaraju 2017). Professor Raghuramaraju then argues that the contributions of hermeneuticians like Gadamer and Ricoeur might best be used not so much to clarify anything about cross-cultural philosophy as such, but instead to alert us to interpretive prejudices that belonging to any tradition may imbue us with about other traditions, or even that different schools within one tradition might entertain for another. He then points out that, given the tendencies of modern comparative thought, even in Daya Krishna and B.K. Matilal, to elevate modern Western traditions relative to their ancient or modern Indian interlocutors. We should take stock of these circumstances before calling for hermeneutic "expansion."

I certainly appreciate all of these insights by Professor Raghuramaraju, particularly the emphasis that Gadamerian or Ricoeurian hermeneutics might best be limited to both the interpretive conditions and perils of prejudice. He is also surely correct in pointing out that representatives of various Western traditions tend to "totalize" Western thought in ways that mask its marked internal differences. I acknowledged this in my original piece when I addressed the extent to which cultural "hybridity" can be resorted to in ways that seemingly

Journal of World Philosophies 2 (Summer 2017): 121-143

Copyright (C) 2017 Douglas L. Berger, Hans-Georg Moeller, A. Raghuramaraju, Paul A. Roth.

e-ISSN: 2474-1795 • http://scholarworks.iu.edu/iupjournals/index.php/jwp• doi: 10.2979/jourworlphil.2.1.09 
ameliorate problems in cross-cultural philosophy, though they don't entirely do so. I would also add that a number of thinkers from, for example, the Bengali Renaissance and the New Confucian revival and the Kyoto School also took up the trope of totalizing "Western" thought in order to stake out their own oppositional identities. But my call for hermeneutic "expansion" was largely a call for the interpreter to expand their own horizons by engaging in cross-cultural dialogue with many other traditions. It may be largely true that "colonialism," in its activities related to cultural appropriation, might be largely absent from Anglo-SaxonContinental philosophical interchange. It's also worth noticing that, in these circumstances many participants both of these movements don't consider what representatives of the other are doing as philosophy at all either, not to mention what goes on in other cultural traditions. Nonetheless, I'm more inclined to believe that those engaged in, for example, cross-cultural thought in South or East Asian contexts, my primary audience in the original piece, ought to explore how those cultural traditions interpreted and appropriated one another's frameworks. One aim of this approach is to create circumstances where contemporary interpreters can engage with cross-cultural interpretive frameworks that did not originate in Western contexts and did not serve the interests of those contexts. One of the great benefits of "expansion" in this sense, I hope, would be not only immersion into different philosophical perspectives, but into different hermeneutic principles than those formulated in the West.

Professor Roth, in his sharply focused and superbly articulated critique of my original piece, asserts that the works of such consequential theorists and philosophers as Geertz, Quine and Davidson ought to play more of a central role in my approach to problems in cross-cultural philosophy. I shall concede that point and will attempt to integrate their works into future writings on this subject. I'm afraid however that Professor Roth attributes a position to me that I don't actually hold in a depiction of what he calls "Berger's paradox." (Maybe I should not be so quick to disown this label. I am honored, as every philosopher ought to be, to suddenly have a special paradox attached to my name.) The worries I expressed in my essay about the "unaccommodating cultural conditions" and "unwitting cultural projections" of a modern interpreter vis-à-vis an ancient or other culture are not tantamount to a belief that ideas from the latter are "untranslatable" into the former. Roth's Davidsonian objection to my essay pits my suspicions of colonial legacies and the hermeneutic circle as impediments to the interpreter's task against my attempts, "without blushing" (Roth 2017), to understand ancient Indian and Chinese texts. He observes that my "practice" of interpreting trumps the questions I raised, the latter of which should undermine the possibility of interpreting to begin with. But this portrayal only holds if I maintain on the one hand that translation is somehow impossible but on the other hand unabashedly go forward with it. Far from believing that ideas from ancient or other cultures are untranslatable in one's own, I rather agree with Professor Roth that there is no fixed or neutral ground upon which to judge the adequacy of translations, and that translations are ongoing negotiations that take place within the moving dynamics of social construction and communication. One could hardly say that Orientalist scholars from the $17^{\text {th }}$ century to the present really didn't produce translations, or that $17^{\text {th }}$ century scholars in the Mughal court did not really translate ancient Sanskrit texts into Persian, or that $6^{\text {th }}$ century Chinese scholars of Sanskrit texts didn't really produce translations of Buddhist literature, or that Jewish scholars of the early centuries before the Common Era did not really produce Greek translations of their Hebrew scriptures. It is of course obvious that all these translations also involved interpretations which made the source texts more amendable to the conceptual frameworks of the audience reading the target languages. In raising the problematics of the legacies of colonialism in Western receptions of various traditions of Asian thought and the difficulties of the hermeneutic circle, I think it's necessary to consciously thematize serious potential dangers to our translation and interpretive efforts in order to avoid pitfalls in understanding and conceptual projection that have many examples in recent centuries. Davidson's own view that we have to be "impositionists" in translating and interpreting the thought of other cultures strikes me as too extreme. It is true that we cannot help but be the interpreters we are, historically and hermeneutically influenced by the languages and cultural dynamics of our own time, and it is

Journal of World Philosophies 2 (Summer 2017): 121-143

Copyright (c 2017 Douglas L. Berger, Hans-Georg Moeller, A. Raghuramaraju, Paul A. Roth.

e-ISSN: 2474-1795 • http://scholarworks.iu.edu/iupjournals/index.php/jwp• doi: 10.2979/jourworlphil.2.1.09 
also true that we can never pretend that we live inside the heads of authors of ancient texts or divine exactly what they meant. But we can nonetheless use the resources of our own cultural inheritance, our own experience as interpreters and all the tools we can find that will help us understand the texts, the historical situations and the social circumstances of ancient and other cultures in order to mitigate impositions, even if we cannot totally eliminate them. Complete opaqueness and untainted clarity are not the only two options in translating and interpreting. If interpreting is the ongoing, dynamic, communicative negotiation that Professor Roth believes, rightly in my view, it is, then the process of that negotiating can include correction and refinement, so that constricted possibilities for understanding can be transformed into enriched possibilities.

Once again, I thank Professors Moeller, Raghuramaraju and Roth for their helpful and critical essays. 


\section{References}

Kwame Anthony Appiah, In My Father's House: Africa in the Philosopby of Culture (New York: Oxford University Press, 1992).

Douglas L. Berger, Encounters of Mind: Luminosity and Personhood in Indian and Chinese Thought (Albany, SUNY Press, 2015).

Douglas L. Berger, "Cross-Cultural Philosophy and Hermeneutic Expansion," Journal of World Philosophies 2, (2017a): 121-5.

Douglas L. Berger, "Symposium Response," Journal of World Philosophies 2, (2017b): 138-40.

James Bohman, Democracy Across Borders (Cambridge, MA: MIT Press, 2007).

James Clifford, and George Marcus, Writing Culture: The Poetics and Politics of Ethnography (Berkeley, CA: University of California Press, 1986).

Donald Davidson, "On the Very Idea of a Conceptual Scheme," Proceedings and Addresses of the American Philosophical Association 47, (1973-1974): 5-20.

William Theodore de Bary, The Trouble with Confucianism (Cambridge and London, Harvard University Press, 1991).

Hans-Georg Gadamer, Truth and Method, trans. Joel Weinsheimer, and Donald G. Marshall (New York, Continuum, 1994), 265-306.

Clifford Geertz, The Interpretation of Cultures (New York: Basic Books, 1973).

Clifford Geertz, Works and Lives: The Anthropologist As Author (Stanford, CA: Stanford University Press, 1988).

Wilhelm Halbfass, India and Europe: An Essay in Understanding (Albany, SUNY Press, 1988), 197-262.

Philip J. Ivanhoe, "Whose Confucius, Which Analects?" Confucius and the Analects: New Essays (Oxford and New York, Oxford University Press, 2002), 119-33.

Daya Krishna, "Comparative Philosophy: What It Is and What It Ought to Be," in Interpreting Across Boundaries: New Essays in Comparative Philosophy, ed. Gerald J. Larson, and Eliot Deutsch (Delhi: Motilal Banarsidass Publishers Pvt. Ltd. 1988), 71-83.

Fung Yu Lan, A History of Chinese Philosophy, trans. Derk Bodde, Vol.s. 1-2 (Princeton, Princeton University Press, 1973).

Gerald Larson, "Introduction," in Interpreting Across Boundaries: New Essays in Comparative Philosophy, ed. Gerald J. Larson, and Eliot Deutsch (Delhi: Motilal Banarsidass Publishers Pvt. Ltd. 1988), 3-18.

ed. John Makeham, Learning to Emulate the Wise: The Genesis of Chinese Philosophy as an Academic Discipline in Twentieth-Century China (Hong Kong: The Chinese University Press, 2012).

Ram Adhar Mall, "Intercultural Philosophy: A Conceptual Clarification," Confluence: Online Journal of World Philosopbies 1, (2014): 67-84.

Pankaj Mishra, From the Ruins of the Empire: The Intellectuals Who Remade Asia (New York: Farrar, Straus \& Giroux, 2012).

Jitendranath N. Mohanty, "On Interpreting Indian Philosophy: Some Problems and Concerns," Essays on Indian Philosophy: Traditional and Modern, Delhi (Oxford etc.: Oxford, 1993), 207-19.

Journal of World Philosophies 2 (Summer 2017): 121-143

Copyright (C 2017 Douglas L. Berger, Hans-Georg Moeller, A. Raghuramaraju, Paul A. Roth.

e-ISSN: 2474-1795 • http://scholarworks.iu.edu/iupjournals/index.php/jwp• doi: 10.2979/jourworlphil.2.1.09 
Hans-Georg Moeller, "Remarks on the Paradox and the Unmarked Space of Cross-Cultural Philosophy," Journal of World Philosophies 2, (2017): 126-9.

Willard Van Orman Quine, Word and Object (Cambridge, MA: MIT Press, 1960).

A. Raghuramaraju, "Rethinking the West," Third Text 19, no. 6, (2005): 595-98.

A. Raghuramaraju, Debates in Indian Philosophy: Classical, Colonial and Contemporary (New Delhi, Oxford University Press, 2006).

A. Raghuramaraju, "Consolidation before Expansion: Revisiting Cross-Cultural Philosophy," Journal of World Philosophies 2, (2017): 130-4.

Paul Ricoeur, Hermeneutics and the Human Sciences, ed. and trans., John B. Thompson (Cambridge: Cambridge University Press, 1981).

Paul A. Roth, "Translation and Understanding: What the Problems Are Not," Journal of World Philosophies 2, (2017): 135-7.

Marshall Sahlins, How "Natives” Think: About Captain Cook, For Example (Chicago, The University of Chicago Press, 1995).

Sor-hoon Tan, "Balancing Conservatism and Innovation: The Pragmatic Analects," Dao Companion to the Analects (Dordrecht, Heidelberg, New York, London: Springer, 2014), 335-54.

Charles Taylor et al., Multiculturalism (Princeton, NJ: Princeton University Press, 1994).

Bryan R. Wilson, Rationality (Evanston, IL: Harper \& Row, 1970).

Peter Winch, "Understanding a Primitive Society," American Philosophical Quarterly 1, (1964): 307-24.

Ludwig Wittgenstein, Philosophical Investigations, 50 th Anniversary Editon (New York: Blackwell, 2001).

Journal of World Philosophies 2 (Summer 2017): 121-143

Copyright (c) 2017 Douglas L. Berger, Hans-Georg Moeller, A. Raghuramaraju, Paul A. Roth.

e-ISSN: 2474-1795 • http://scholarworks.iu.edu/iupjournals/index.php/jwp• doi: 10.2979/jourworlphil.2.1.09 
Douglas L. Berger is Professor and Chair of the Philosophy Department at Southern Illinois University, Carbondale, USA. He has written many essays on South Asian, Buddhist, and Chinese philosophical traditions as well as on 19th-century continental thought. His major monographs are: Encounters of Mind: Luminosity and Personhood in Indian and Chinese Thought (SUNY Press, Albany, 2015), Nothingness in Asian Philosophy, co-edited with JeeLoo Liu (Routledge Press, London/New York, 2014), and "The Veil of Maya:" Schopenhauer's System and Early Indian Thought (Global Academic Publishing, SUNYBinghamton, 2004). He has served as the President of the Society of Asian and Comparative Philosophy and is the chief editor of the University of Hawai'i book series Dimensions of Asian Spirituality.

Hans-Georg Moeller is Professor of Philosophy at the University of Macau. His research focuses on Chinese and Comparative Philosophy and on Social and Political Thought. He is the author of The Philosophy of the Daodejing, The Moral Fool: A Case for Amorality, and The Radical Lubmann (all published by Columbia University Press, New York) and other academic books and articles.

A. Raghuramaraju is a professor of Philosophy at the University of Hyderabad. His publications include: Debates in Indian Pbilosophy (2006; got the Choice Outstanding Academic Title in 2007); Enduring Colonialism: Classical Presences and Modern Absences in Indian Philosophy (2009); Modernity in Indian Social Theory (2011); Philosophy and India: Ancestors, Outsiders and Predecessor (2015). His edited volumes include: Debating Gandhi: A Reader (2006) and Debating Vivekananda: A Reader (2015) (all six books are published by Oxford University Press, New Delhi); He has also edited Ramchandra Gandhi: The Man and His Philosophy (Routledge 2009) and Seven Sages: Selected Essays of Ramchandra Gandhi (Penguin 2015). Raghuramaraju has published papers in Third Text, IESHR, EPW, AI and Society, JICPR, IPQ, Social Scientist. His essay the "Rethinking the West" is included in Documenta Magazine 12, 2007.

Paul A. Roth is Distinguished Professor in the Department of Philosophy, University of CaliforniaSanta Cruz. He has published widely on philosophy of history (primarily on the topic of historical explanation), philosophy of social science, naturalized epistemology, and W. V. Quine. Forthcoming work includes "Essentially Narrative Explanations" (to be published in Studies in History and Philosopby of Science) and a volume devoted to Roth's writings on philosophy of history (forthcoming in the Poznan Studies in Philosophy series). 